\title{
Cyclo(Tyr-Tyr) Dipeptidinin Teorik IR, Raman ve Moleküler Yapı Analizi
}

\author{
Sefa ÇELİK ${ }^{* 1}$, Sevim AKYÜZ² ${ }^{\circledR}$, Ayșen E. ÖZEL ${ }^{3}$ \\ 1,3̇̇stanbul Üniversitesi, Fen Fakültesi, Fizik Bölümü, 34134, İstanbul, Türkiye \\ 2İstanbul Kültür Üniversitesi, Fen-Edebiyat Fakültesi, Fizik Bölümü, 34156, İstanbul, Türkiye
}

(Alınış / Received: 16.02.2021, Kabul / Accepted: 16.05.2021, Online Yayınlanma / Published Online: 15.08.2021)

\section{Anahtar Kelimeler Cyclo(Tyr-Tyr), Dipeptit, Diketopiperazin, Konformasyon analizi, Moleküler modelleme}

\begin{abstract}
Özet: Bu çalışmada HT-29, Hela ve MCF-7 hücre hatlarına karşı antikanser etki gösteren Cyclo(Tyr-Tyr) dipeptidinin olası en kararlı yedi konformasyonu tirozin aminoasitlerinin $\chi$ yan zincir dihedral açllarına bağlı olarak konformasyon analizi yapılarak belirlenmiștir. Konformasyon analizi sonrasında belirlenen konformasyonlara ait geometrik yapılar, yan zincire ait dihedral açıdaki değişimler ve konformerlerin toplam ve bağıl enerjileri ile bu konformasyonların toplam enerjilerine katkı sağlayan van der Waals, elektrostatik, torsiyon enerji katkıları ayrı ayrı hesaplanmıştır. Konformasyon analizi ile belirlenen en kararlı konformer, Gaussian03 programı kullanılarak, DFT (Density Functional Teory), B3LYP fonksiyoneli ve $6-31++G(d, p)$ baz seti ile optimize edilmiş ve optimize yapının temel titreşim dalga sayıları aynı teori düzeyinde hesaplanmıştır. Ayrıca, IR şiddetleri, Raman aktiviteleri, potansiyel enerji dağılımları MOLVIB programı kullanılarak saptanmıș, Simirra programı ile ölçeklendirilmiş Raman aktiviteleri, Raman şiddetlerine dönüştürülmüştür. Ek olarak bu dipeptidin dimerik formu oluşturulmuş ve DFT/B3LYP/6-31G(d,p) teori düzeyinde optimize edilerek halka yapıya ait $\mathrm{w}, \varphi, \Psi$ dihedral açıları monomer form ile karşılaştırmalı olarak verilmiştir. Dimerik yapının oluşumunda rol oynayan moleküller arası hidrojen bağları belirlenmiştir.
\end{abstract}

\section{Theoretical IR, Raman and Molecular Structure Analysis of Cyclo (Tyr-Tyr) Dipeptide}

\section{Keywords}

Cyclo(Tyr-Tyr),

Dipeptide,

Diketopiperazine, Conformational analysis, Molecular modeling

\begin{abstract}
In this study, the most stable seven conformations of the Cyclo (Tyr-Tyr) dipeptide, which shows anticancer effect against HT-29, Hela, and MCF-7 cell lines, were determined by conformational analysis based on $\chi$ side-chain dihedral angles of the two tyrosine amino acids. The geometric structures of the conformations, determined after the conformation analysis, the changes in the dihedral angle of the side-chain, the total and relative energies of the conformers, and the van der Waals, electrostatic and torsion energy contributions, that contribute to the total energies, were calculated separately. The most stable conformer, determined by conformation analysis, was then optimized using density functional theory (DFT), B3LYP functional and the $6-31++G(d, p)$ basis set by using Gaussian03 program, and the fundamental vibrational wavenumbers of the optimized structure were calculated at the same level of theory. In addition, IR intensities, Raman activities, potential energy distributions were determined using the MOLVIB program, and the scaled Raman activities scaled were transformed into Raman intensities by Simirra program. Furthermore, the dimeric form of the dipeptide was created and optimized at the DFT/B3LYP/6-31G(d,p) level of theory. The $w, \varphi, \Psi$ dihedral angles of the ring structure were given comparatively with the monomer form calculated with the same basis sets. The intermolecular hydrogen bonds that play role in the formation of the dimeric structure have been determined.
\end{abstract}

\section{Giriş}

Moleküler yapı ile molekülün fiziksel, kimyasal ve biyolojik özellikleri arasındaki ilişki nedeniyle molekülün konformasyonunun belirlenmesi son derece önemlidir. Konformasyonel analiz ile esnek biyomoleküllerin ve ilaçların konformasyonel karakteristiği ve konformasyonel esneklik ile aktivite 
arasındaki ilişki belirlenebilmektir [1]. Son yıllarda küçük peptitlerin biyolojik işlevde kritik öneme sahip modülatörlerin sınıfını oluşturduğuna dair çok sayıda çalışma yapılmıştır. Çok sayıda küçük peptidin, endokrin sistemdeki hormonların ve merkezi sinir sistemindeki nöromodülatörlerin veya nörotransmiterlerin biyolojik rolüne hizmet ettiği düşünülmektedir. Cinsel olgunlaşma ve üreme, enzim inhibisyonu, kan basıncı regülasyonu, glikoz metabolizması ve depolanması, termal kontrol, tokluk, analjezi ve öğrenme ve hafıza gibi çeşitli biyolojik fonksiyonların artık peptitler tarafindan düzenlendiği ve modüle edildiği düșünülmektedir. Hücreler arası iletişimde ve diğer biyolojik süreçlerde küçük peptitlerin önemi göz önünde bulundurulduğunda, bu moleküller tarafından bilgi aktarımı için temelde yatan fiziksel ve kimyasal temele dayanan bir anlayış geliștirmeye büyük ilgi vardır. Canlı süreçler genellikle öklid uzayının üç boyutu (konformasyon ve topoloji) ve zaman olmak üzere dört boyuta sahiptir. Bu nedenle biyolojik canlılığ ve değișimi bașlatmak ve sürdürmek için canlı sistemleri oluşturan moleküllerin üç boyutlu özellikleri ve üç boyutta meydana gelen değişimler açısından biyolojik süreçleri anlamak gerekir [2].

Diketopiperazin halka yapısına sahip olan halka dipeptitler ilk olarak 1900'lerin başlarında karakterize edilmiştir. İnsanlarda ve mikroorganizmalarda doğal olarak olușan halka dipeptitlerin keşfedilmesinden bu yana biyolojik aktivitelerine ait araştırmalar gittikçe artmaktadır [3]. Aromatik yan zincirlere sahip amino asitlerden oluşan halka dipeptitlerin yapısının aydınlatılması, aromatik halkaların biyoaktif moleküllerde bulunması nedeniyle daha ilgi çekici bir alan olmuştur [4].

İyonoforlar, iyon kanallar,, nükleik asit interkalatörleri vb. gibi davranan diğer birçok küçük halka peptit antibiyotiğinin konformasyonel özellikleri ayrıntılı olarak incelenmiştir [5]. Enzim inhibisyonu, bağışıklık sistemindeki aktivite vb. dahil olmak üzere çeşitli diğer biyolojik aktivitelere sahip halka peptitler üzerinde de çalışmalar yapılmıştır [2]. Cyclo(-Pro-Tyr) dipeptidi üzerine yapılan çalışmada PI3K, AKT'nin fosforilasyonunu inhibe ettiği ve PTEN ekspresyonunu arttırdığı bulunmuştur. Bu sonuçlar, Cyclo(-Pro-Tyr) dipeptidi'nin, mitokondriyal disfonksiyon yoluyla apoptozu başlatarak ve HepG2 hücrelerinde PI3K/Akt sinyal yolunu regüle ederek, normal fibroblast hücreleri üzerinde toksisite etkisi olmadan anti-kanser etkisine sahip olabileceği öne sürülmüștür. $\mathrm{Bu}$ nedenle Cyclo(-Pro-Tyr), hepatoselüler karsinomu tedavi etmek için potansiyel bir alternatif terapötik ajan olarak geliştirilebilir [6].

Endojen nöropeptid cyclo-L-prolylglycine, nörotrofik faktör seviyesi üzerindeki olumlu etkisinden ve büyüme faktörü-1 ve AMPA reseptörlerinin aktivitesinin modülasyonundan kaynaklanabilen mnemotropik ve nöroprotektif özelliklere sahiptir. cyclo-L-prolylglycine, incelenen hücre hatlarında Ki67 düzeyini ve hücrelerin hücre döngüsünün G1 ve G2 fazları üzerindeki dağılımını etkilemediği ancak S fazı hücrelerinin yüzdesini azalttığı bulunmuştur. Aynı zamanda, cyclo-L-prolylglycine, koruyucu etkisinin bir mekanizması olabilecek erken apoptotik hücrelerin sayısını azalttığı gösterilmiştir [7].

Cys-Cys ve Cys-Arg ACE inhibitör dipeptitlerdir. ACE kan basıncının düzenlenmesinde rol alan bir enzimdir [8]. Gao ve arkadaşları tarafından yapılan çalışmada bu dipeptitler ile ACE arasındaki etkileşme moleküler kenetlenme ile belirlenmiştir. $\mathrm{Bu}$ hesaplama sonucunda Cys-Cys 'in karboksil oksijeni ile Zn (II) arasında koordinasyon, Ala354 (O), Ala356 (HN) ve Tyr523 (OH) kalıntılarıyla (rezidüleriyle) hidrojen bağları ve His387 (NE2) kalıntısıyla ACE nin aktif bölgesinde bir yumak oluşturduğu gösterilmiştir. Ayrıca Cys-Arg ile ACE nin aktif bölgesi arasında His353, Ala354, Glu384, Glu403 ve Arg522 rezidüleri ile 5 Hidrojen bağı etkileșmesinin olduğu gösterilmiştir. Bu bulgular, Cys-Cys'in yeni güçlü bir ACE inhibitörü olarak düşünülebileceğini ve karboksil oksijeni ile Zn (II) arasındaki koordinasyonun ACE inhibitör potansiyelini tanımlamada önemli bir rol oynadığını vurgulamıștır [9].

Cys-Phe, Glu-Tyr, Met-Phe ve Phe-Glu dipeptitlerinin ACE önleyici etkiye sahip oldukları Wu ve arkadaşları tarafından yapılan çalışmada bulunmuştur [10]. Nakashima ve ark. tarafından ACE inhibitör Met-AsnPro-Pro-Lys ve Ile-Thr-Thr-Asn-Pro peptitleri üzerine yapılan çalışmada antihipertansif aktivite gösterdikleri bulunmuștur [11]. Lee ve ark. tarafindan Gly-Asp-Leu-Gly-Lys-Thr-Thr-Thr-Val-SerAsn-Trp-Ser-Pro-Pro-Lys-Try-Lys-Asp-Thr-Pro peptidi üzerine yapılan çalışmada sistolik kanbasıncı üzerinde baskılayıcı etkiye sahip olduğu bulunmuştur [12].

Kimyasal yapılarına göre ilaç olarak ticarileşmiş peptitlerden bazılarını şu şekilde sıralayabiliriz;

-Küçük peptitler içeren: Ninlar $®$, Macrilen $®$ vb;

-Orta ölçekli peptidler içeren: Giapreza $\AA$, Scenesse $\AA$, vb;

-Homodetik halka peptidler içeren: Vyleesi $®, v b$; -Molekül içi ve moleküller arası disülfit içeren peptitler: Parsabiv®, Trulance $®$, vb;

-Büyük yapılı peptitler içeren: Tymlos®, Lixisenatide $\AA$, vb [13] .

Kilian ve ark. tarafından yapılan çalışmada cyclo(tyrtyr) dipeptidinin HT-29, Hela ve MCF-7 hücre hatlarına karşı antikanser aktivite gösterdiği bulunmuştur [14]. Rajput ve ark. tarafından cyclo(tyr-tyr) türevleri üzerine yapılan çalışma da ise antimikrobiyal aktiviteye sahip olduğu gözlenmiștir [15]. 
$\mathrm{Bu}$ dipeptidin sahip olduğu antikanser ve antimikrobiyal aktiviteyi açlklayabilmek için üç boyutlu yapısının ve en kararlı konformerlerin belirlenmesi gerekmektedir.

Cyclo(tyr-tyr) dipeptidinin en kararlı konformasyonlarının ve dimerik formunun yapısının aydınlatılmasına yönelik literatürde mevcut bir çalışmaya rastlanılmamıştır.

Teorik konformasyon analizi, moleküler mekanik hesaplamayı temel alarak ve Ramachandran haritalarını kullanarak en olası konformasyonları belirleyen bir metotdur. Ramachandran haritaları olarak adlandırılan aminoasitlerin sahip olduğu $\varphi, \psi$ ve $\chi$ dihedral açıları en kararlı konformasyonların belirlenmesinde önemli role sahiptir [16].

$\mathrm{Bu}$ çalışmada Cyclo(Tyr-Tyr) dipeptidinin olası en kararlı yedi konformasyonu hesaplanmış ve yedi konformere ait geometrik yapılar, yan zincire ait dihedral açıdaki değişim ve konformerlerin enerjileri Godjaev ve ark. tarafından yazılan moleküler mekanik hesaplama programı kullanılarak hesaplanmıștır [17]. Van der Waals, elektrostatik, torsiyon enerji katkıları ve toplam enerjileri hesaplanmıştır. Cyclo(Tyr-Tyr) dipeptidinin dimerik formu, kuantum kimyasal ab-initio hesaplamalarla optimize edilerek halka yapıya ait dihedral açı değerleri belirlenerek monomer form ile karşılaştırılmıştır.

\section{Materyal ve Metot}

Cyclo(Tyr-Tyr) dipeptidinin en olası konformasyonları teorik konformasyon analizi ile belirlenmiştir. Bu hesaplama yöntemi, Van der Waals etkileşimleri, elektrostatik etkileşimleri, molekül içi hidrojen bağları ve yan zincirlerin tekli bağları etrafında sınırlı dönülerini kapsamaktadır.

Lennard-Jones potansiyeli, Scott ve Scheraga tarafından önerilen veriye bağlı olarak bağ yapmayan etkileşimleri hesaplamak için kullanılmıştır [18]. Elektrostatik enerji ise monopol yaklaşıma bağlı olarak hesaplanmıștır [18]. Yan zincir bağlarını döndürmek üzere olan torsiyon potansiyeli ve bariyer enerjileri Scheraga tarafından verilmiştir [19]. Bağ uzunlukları, açıları ve dihedraller, Corey ve Pauling tarafından önerildiği gibi alınmış ve sabit tutulmuştur [19]. Cyclo(Tyr-Tyr) dipeptidinin konformasyonel analizi, Godjayev ve arkadaşları tarafindan yazılan program kullanılarak belirlenmiştir [17].

Tirozin aminoasidinin $\chi$ yan zincir dihedral açları kullanılarak teorik konformasyon analizi ile en olası yedi konformasyon belirlenmiştir. Bunlar arasından en düşük enerjili konformer Gaussian03 programı [20], DFT metodu [21], B3LYP fonksiyoneli ve 6$31 G(d, p)$ ve $6-31++G(d, p)$ baz setleri kullanılarak optimize edilerek mulliken yükleri hesaplanmıștır.
Daha sonra iki monomerik form biraraya getirilerek elde edilen dimerik form DFT metodu, B3LYP fonksiyoneli ve 6-31G(d,p) baz seti ile optimize edilmiştir.

Monomerik forma ait en kararlı konformasyon, Gaussian03 programina tanitılarak DFT (Density Functional Theory) yöntemi, B3LYP fonksiyonu, 6$31++G(d, p)$ baz seti ile geometri optimizasyonu yapılarak, molekülün temel titreşim dalga sayıları hesaplanmıștır. Cyclo-Tyr-Tyr dipeptidinin harmonik kuvvet alanı, MOLVIB programı kullanılarak ölçeklendirilmiş kuantum mekanik kuvvet alanı yöntemi ile B3LYP/6-31++G(d,p) baz setinde değerlendirilmiştir [22, 23]. IR şiddetleri, Raman aktiviteleri, potansiyel enerji dağılımları MOLVIB programı kullanılarak hesaplanmıștır. Simirra programı ile ölçeklendirilmiş Raman aktiviteleri, Raman şiddetlerine dönüştürülmüştür [24].

DFT/B3LYP/6-31++G(d,p) teori $\quad$ seviyesi kullanılmıştır:

$\mathrm{O}-\mathrm{H}$ bağ gerilmesi $0.87 ; \mathrm{N}-\mathrm{H}$ bağ gerilmesi $0.89 ; \mathrm{C}-\mathrm{H}$ bağ gerilmesi 0.91 ; $\mathrm{C}=0$ bağ gerilmesi $0.86 ; 0-\mathrm{H}, \mathrm{N}-\mathrm{H}$ and C-H deformasyon 0.92; diğerleri için 0.98.

\section{Bulgular}

Corey, Degeilh ve Dorset tarafindan yapılan çalışmalarda diketopiperazinin (DKP) kristal yapısı bulunmuş ve halkanın düzlemsel geometriye sahip olduğu belirlenmiștir [25-27]. Bu nedenle cyclo(tyrtyr) dipeptidinin konformasyon analizinde, DKP halkasının düzlemsel olduğu varsayılarak analiz edilmiştir. Cyclo(tyr-tyr) için konformasyon enerjisi, $\chi 11, \chi 12, \chi 13, \chi 21, \chi 22$ ve $\chi 23$ ün bir fonksiyonu olarak hesaplanmıștır. Konformasyon analizi öncesi ve sonrası yedi olası kararlı konformasyonun dihedral açıları, enerjileri ve bağıl enerjileri Tablo 1 'de verilmiştir. Ayrıca bu en düşük enerjiye sahip olası yedi konformer Şekil 1'de gösterilmiştir. Konformasyonların van der Waals, elektrostatik, torsiyon enerji katkıları ve toplam enerjileri Tablo 2'de verilmiştir. Cyclo(Tyr-Tyr) dipeptidinin DFT/B3LYP/6-31++G(d,p) teori seviyesinde hesaplanan optimize geometrisi, yan zincir dihedral açıların gösterimi ve yük dağılımı Şekil 2 ve Şekil 3' de verilmiştir. İki monomerik cyclo(tyr-tyr) dipeptidinin hidrojen bağı yaparak bir araya gelmesi sonucu elde edilen dimerik formun DFT/B3LYP/6$31 \mathrm{G}(\mathrm{d}, \mathrm{p})$ teori seviyesinde optimizasyonu sonucunda elde edilen moleküler geometrisi Şekil 4'de verilmiştir ve monomerik ve dimerik formlara ait DKP halkası üzerindeki dihedral açılardaki değişim karşılaştırmalı olarak Tablo 3'de verilmiştir. Cyclo(Tyr-Tyr) dipeptidinin monomerik formuna ait hesaplanan dalgasayıları $\left(\mathrm{cm}^{-1}\right)$, IR ve Raman şiddetleri ve potansiyel enerji dağılımı (PED) Tablo 4'de verilmiștir. 
Tablo 1. Cyclo(Tyr-Tyr) dipeptidinin en kararlı yedi konformasyonuna ait yan zincir dihedral açı değerleri

\begin{tabular}{|c|c|c|c|c|c|c|c|c|c|}
\hline Konformer & $\begin{array}{l}\text { Bağll Enerji } \\
\text { (kcal/mol) }\end{array}$ & $\begin{array}{c}\text { Enerji } \\
\text { (kcal/mol) }\end{array}$ & & $\chi 11$ & $\times 12$ & $\chi 13$ & $\times 21$ & $\times 22$ & $\times 23$ \\
\hline \multirow{2}{*}{1} & \multirow[t]{2}{*}{0} & \multirow{2}{*}{-4.72} & GİRIŞ̧ & -60.0 & 90.0 & 60.0 & 60.0 & 90.0 & 60.0 \\
\hline & & & ÇIKIŞ & -52.6 & 97.9 & -0.24 & 62.7 & 92.6 & -0.30 \\
\hline \multirow{2}{*}{2} & \multirow[t]{2}{*}{0.2} & \multirow{2}{*}{-4.70} & GİRİŞ & 60.0 & -90.0 & 60.0 & -60.0 & -90.0 & -60.0 \\
\hline & & & ÇIKIŞ & 62.7 & -87.9 & -0.21 & -53.5 & -82.5 & 0.09 \\
\hline \multirow{2}{*}{3} & \multirow[t]{2}{*}{1.62} & \multirow{2}{*}{-3.10} & GİRIŞ & 180.0 & 90.0 & 180.0 & 60.0 & -90.0 & 60.0 \\
\hline & & & ÇIKIŞ & 196.4 & 64.8 & 179.8 & 63.1 & -83.4 & -0.33 \\
\hline \multirow{2}{*}{4} & \multirow[t]{2}{*}{1.71} & \multirow{2}{*}{-3.01} & GİRIŞ̧ & 60.0 & 90.0 & 60.0 & 180.0 & 90.0 & 60.0 \\
\hline & & & ÇIKIȘ & 62.9 & 95.9 & -0.33 & 196.7 & 64.5 & -0.32 \\
\hline \multirow{2}{*}{5} & \multirow[t]{2}{*}{2.66} & \multirow{2}{*}{-2.06} & GİRİŞ & -60.0 & -90.0 & 180.0 & -60.0 & -90.0 & 180.0 \\
\hline & & & ÇIKIȘ & -57.1 & -80.8 & 179.7 & -56.9 & -80.8 & 179.7 \\
\hline \multirow{2}{*}{6} & \multirow[t]{2}{*}{4.08} & \multirow{2}{*}{-0.64} & GİRISŞ & 180.0 & 90.0 & 180.0 & -60.0 & 90.0 & 60.0 \\
\hline & & & ÇIKIŞ & 197.4 & 64.7 & 179.8 & -57.4 & 97.6 & 0.43 \\
\hline \multirow[b]{2}{*}{7} & \multirow[t]{2}{*}{4.12} & \multirow{2}{*}{-0.60} & GİRİŞ & -60.0 & 90.0 & 60.0 & 180.0 & -90.0 & 60.0 \\
\hline & & & ÇIKIȘ & -57.5 & 98.0 & -0.25 & 198.3 & -115.2 & -0.21 \\
\hline
\end{tabular}

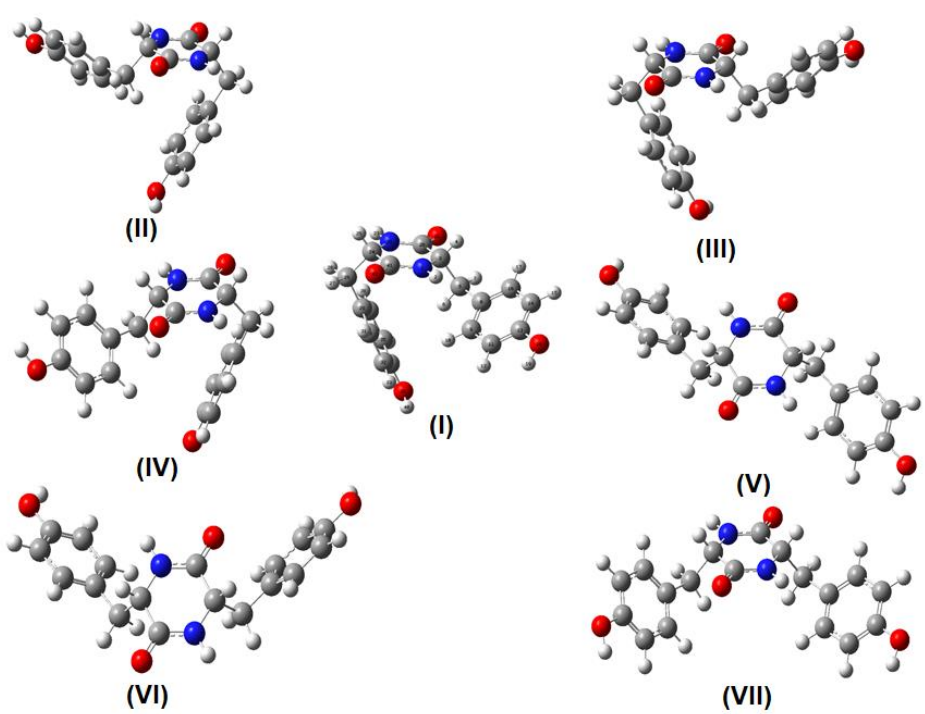

Şekil 1. Cyclo(Tyr-Tyr) dipeptidinin teorik konformasyon analizi sonrasında elde edilen en kararlı yedi konformasyonu

Tablo 2. Cyclo(Tyr-Tyr) dipeptidinin en kararlı yedi konformerine ait enerji katkıları (kcal/mol)

\begin{tabular}{|c|c|c|c|c|c|}
\hline Konformer & EvWalls & Eelektrostatik & Etorsiyon & Etoplam & Ebağll \\
\hline 1 & -4.30 & -0.55 & 0.13 & -4.72 & 0 \\
\hline 2 & -4.25 & -0.55 & 0.10 & -4.70 & 0.2 \\
\hline 3 & -3.08 & -0.56 & 0.54 & -3.10 & 1.62 \\
\hline 4 & -3.02 & -0.55 & 0.56 & -3.01 & 1.71 \\
\hline 5 & -1.55 & -0.55 & 0.04 & -2.06 & 2.66 \\
\hline 6 & -0.68 & -0.55 & 0.59 & -0.64 & 4.08 \\
\hline 7 & -0.69 & -0.55 & 0.65 & -0.60 & 4.12 \\
\hline
\end{tabular}

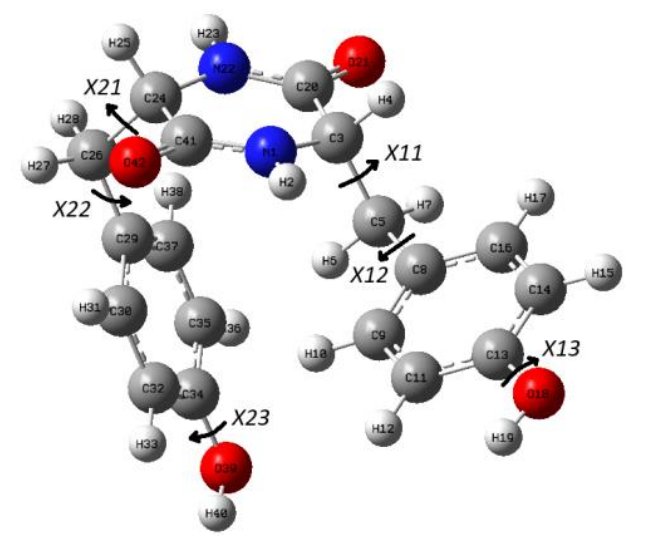

Şekil 2. Cyclo(Tyr-Tyr) dipeptidinin DFT/B3LYP/6-31++G(d,p) teori seviyesinde hesaplanan optimize geometrisi ve yan zincir dihedral açıların gösterimi 


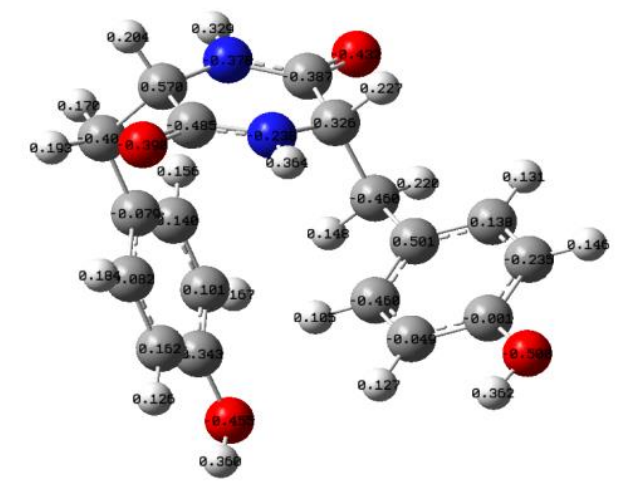

Şekil 3. Cyclo(Tyr-Tyr) dipeptidinin DFT/B3LYP/6-31++G(d,p) teori seviyesinde hesaplanan optimize geometrisinin yük dağılımı

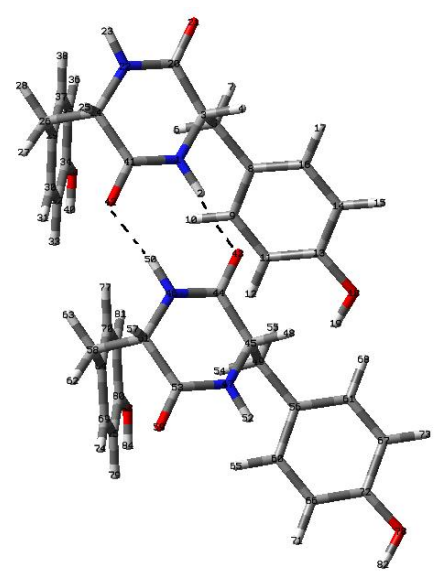

Şekil 4. Cyclo(Tyr-Tyr) dipeptidinin dimerik formunun DFT/B3LYP/6-31G(d,p) teori seviyesinde hesaplanan optimize geometrisi

Tablo 3. Cyclo(Tyr-Tyr) dipeptidinin DKP halkası üzerindeki dihedral açılardaki $\left({ }^{0}\right)$ değişim

\begin{tabular}{ccccccc}
\hline Cyclo(Tyr-Tyr) & $\mathrm{w}_{1}(\mathrm{~N} 1-\mathrm{C} 41)$ & $\mathrm{w}_{2}(\mathrm{C} 20-\mathrm{N} 22)$ & $\varphi_{1}(\mathrm{~N} 1-\mathrm{C} 3)$ & $\varphi_{2}(\mathrm{~N} 22-\mathrm{C} 24)$ & $\Psi_{1}(\mathrm{C} 3-\mathrm{C} 20)$ & $\Psi_{2}(\mathrm{C} 24-\mathrm{C} 41)$ \\
\hline $\begin{array}{c}\text { Monomer } \\
\text { DFT-B3LYP/6-31++G(d,p) }\end{array}$ & -8.32 & -5.78 & 14.42 & 11.96 & -6.94 & -4.76 \\
$\begin{array}{c}\text { Monomer } \\
\text { DFT-B3LYP/6-31G(d,p) } \\
\begin{array}{c}\text { Dimer } \\
\text { DFT-B3LYP/6-31G(d,p) }\end{array}\end{array}$ & -8.25 & -5.78 & 13.37 & 10.98 & -5.97 & -3.85 \\
\hline
\end{tabular}

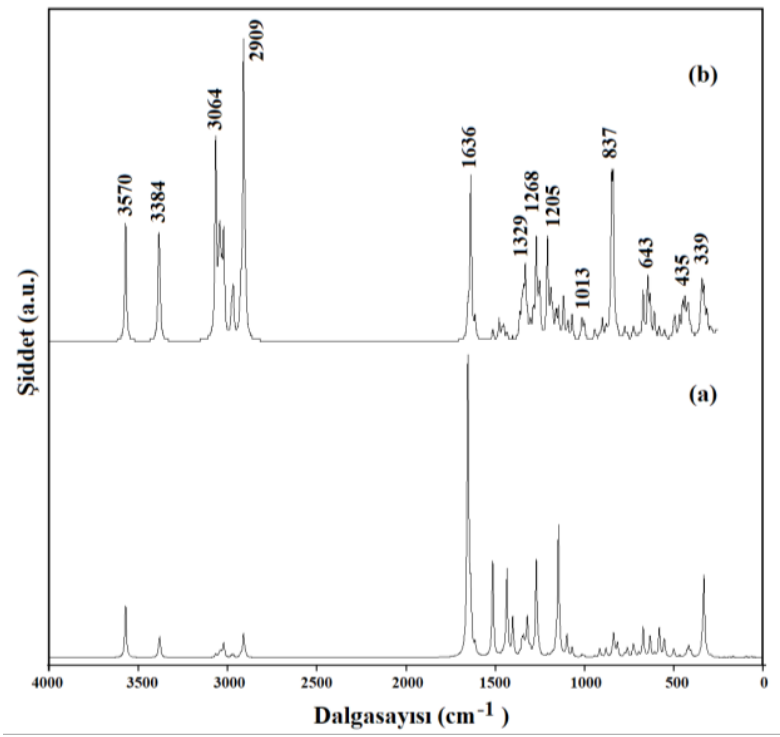

Şekil 5. Cyclo(Tyr-Tyr) dipeptidinin monomerik formunun DFT/B3LYP/6-31++G(d,p) teori seviyesinde hesaplanan IR (a) ve Raman (b) spektrumu 
Tablo 4. Cyclo(Tyr-Tyr) dipeptidinin monomerik formuna ait hesaplanan dalgasayıları $\left(\mathrm{cm}^{-1}\right)$, hesaplanan IR ve Raman şiddetleri ve potansiyel enerji dağılımı (PED)

\begin{tabular}{|c|c|c|c|}
\hline \multicolumn{4}{|c|}{ B3LYP/6-31++G(d,p) } \\
\hline$v^{\mathrm{S}}$ & I(IR) & $\mathrm{I}(\mathrm{Ra})$ & PED \% \\
\hline 3571 & 73 & 38 & $\nu_{\mathrm{OH}}(100)$ \\
\hline 3570 & 54 & 39 & $v_{\mathrm{OH}}(100)$ \\
\hline 3384 & 17 & 36 & $v_{\mathrm{NH}}(98)$ \\
\hline 3378 & 44 & 25 & $v_{\mathrm{NH}}(98)$ \\
\hline 3066 & 4 & 65 & $\nu_{\mathrm{CH}}(97)$ \\
\hline 3064 & 5 & 66 & $v_{\mathrm{CH}}(94)$ \\
\hline 3050 & 3 & 30 & $v_{\mathrm{CH}}(98)$ \\
\hline 3043 & 7 & 40 & $v_{\mathrm{CH}}(99)$ \\
\hline 3038 & 9 & 34 & $v_{\mathrm{CH}}(100)$ \\
\hline 3030 & 7 & 29 & $v_{\mathrm{CH}}(94)$ \\
\hline 3020 & 20 & 38 & $v_{\mathrm{CH}}(99)$ \\
\hline 3020 & 15 & 38 & $v_{\mathrm{CH}}(99)$ \\
\hline 2976 & 5 & 14 & $v_{\mathrm{CH}}(99)$ \\
\hline 2967 & 6 & 19 & $v_{\mathrm{CH}}(100)$ \\
\hline 2925 & 8 & 24 & $v_{\mathrm{CH}}(100)$ \\
\hline 2909 & 48 & 100 & $v_{\mathrm{CH}}(99)$ \\
\hline 2908 & 10 & 97 & $v_{\mathrm{CH}}(99)$ \\
\hline 2898 & 9 & 33 & $v_{\mathrm{CH}}(99)$ \\
\hline 1653 & 418 & 13 & $v_{\mathrm{CO}}(70)+v_{\mathrm{CN}}(13)+\delta_{\mathrm{CNH}}(5)$ \\
\hline 1649 & 394 & 15 & $v_{\mathrm{CO}}(68)+v_{\mathrm{CN}}(14)$ \\
\hline 1636 & 59 & 55 & $v_{\mathrm{CC}}(59)$ \\
\hline 1635 & 63 & 55 & $\operatorname{vcc}(59)$ \\
\hline 1611 & 13 & 9 & $v_{\mathrm{CC}}(65)$ \\
\hline 1611 & 11 & 9 & $v_{\mathrm{CC}}(64)$ \\
\hline 1512 & 142 & 4 & $v \operatorname{co}(8)+v \operatorname{cc}(19)$ \\
\hline 1512 & 89 & 4 & $v_{\mathrm{CO}}(8)+v_{\mathrm{CC}}(19)$ \\
\hline 1477 & 4 & 8 & $v_{\mathrm{CN}}(27)+v_{\mathrm{CC}}(17)+v_{\mathrm{CO}}(8)+\delta_{\mathrm{CNH}}(7)$ \\
\hline 1460 & 4 & 5 & $\delta_{\mathrm{HCH}}(27)+\Gamma_{\mathrm{NCCH}}(13)+\Gamma_{\mathrm{CCCH}}(13)+\delta_{\mathrm{CCH}}(6)$ \\
\hline 1450 & 8 & 6 & $\delta_{\mathrm{HCH}}(20)+\delta_{\mathrm{CCH}}(6)+\Gamma_{\mathrm{CCCH}}(6)+\Gamma_{\mathrm{NCCH}}(6)+v_{\mathrm{CO}}(5)+\Gamma_{\mathrm{HCCH}}(5)$ \\
\hline 1436 & 12 & 3 & $v_{\mathrm{CC}}(25)+\delta_{\mathrm{COH}}(5)$ \\
\hline 1435 & 6 & 3 & $\nu_{\mathrm{CC}}(29)+\delta_{\mathrm{COH}}(6)+\delta_{\mathrm{CCH}}(5)$ \\
\hline 1432 & 198 & 3 & $v_{\mathrm{CN}}(33)+v_{\mathrm{CO}}(17)$ \\
\hline 1400 & 93 & 2 & $\delta_{\mathrm{CNH}}(48)+v_{\mathrm{CC}}(15)$ \\
\hline 1360 & 7 & 10 & $\delta_{\mathrm{CNH}}(33)+v_{\mathrm{CN}}(17)$ \\
\hline 1347 & 32 & 16 & $v_{\mathrm{CC}}(65)$ \\
\hline 1346 & 1 & 16 & $\operatorname{vcc}(66)$ \\
\hline 1339 & 35 & 19 & $v_{\mathrm{CC}}(14)+v_{\mathrm{CN}}(7)+\delta_{\mathrm{CCH}}(5)$ \\
\hline 1329 & 18 & 26 & $\delta_{\mathrm{CCH}}(20)+v_{\mathrm{CC}}(17)$ \\
\hline 1318 & 91 & 12 & $v_{\mathrm{CN}}(20)+\delta_{\mathrm{CNH}}(7)$ \\
\hline 1304 & 13 & 7 & $\delta_{\mathrm{CCH}}(48)+\delta_{\mathrm{COH}}(8)$ \\
\hline 1300 & 6 & 8 & $\delta_{\mathrm{CCH}}(51)+\delta_{\mathrm{COH}}(8)$ \\
\hline 1284 & 6 & 12 & $v_{\mathrm{CN}}(34)+\delta_{\mathrm{CNH}}(6)$ \\
\hline 1268 & 124 & 35 & $v_{\mathrm{CO}}(56)+v_{\mathrm{CC}}(13)$ \\
\hline 1268 & 109 & 35 & $v_{\mathrm{CO}}(55)+v_{\mathrm{CC}}(8)$ \\
\hline 1255 & 14 & 17 & $v_{\mathrm{CC}}(13)+\delta_{\mathrm{cCH}}(18)$ \\
\hline 1248 & 2 & 20 & $v_{\mathrm{CC}}(20)+\delta_{\mathrm{CCH}}(26)$ \\
\hline 1205 & 3 & 35 & $\operatorname{vcc}(41)$ \\
\hline 1205 & 3 & 35 & $v_{\mathrm{CC}}(41)$ \\
\hline 1187 & 2 & 18 & $\delta_{\mathrm{CCH}}(8)+v_{\mathrm{CC}}(21)$ \\
\hline 1177 & 6 & 13 & $\delta_{\mathrm{CCH}}(28)$ \\
\hline 1158 & 16 & 11 & $\delta_{\mathrm{CCH}}(64)$ \\
\hline 1156 & 13 & 11 & $\delta_{\mathrm{CCH}}(63)$ \\
\hline 1144 & 197 & 12 & $\delta$ сон $(66)+v_{\mathrm{cc}}(5)$ \\
\hline 1143 & 120 & 12 & $\delta_{\mathrm{COH}}(66)+v_{\mathrm{CC}}(5)$ \\
\hline 1116 & 1 & 15 & $v_{\mathrm{CN}}(28)$ \\
\hline 1096 & 52 & 5 & $\delta_{\mathrm{cCH}}(12)+v_{\mathrm{CC}}(6)$ \\
\hline 1090 & 2 & 7 & $\delta_{\mathrm{CCH}}(7)+v_{\mathrm{CC}}(11)$ \\
\hline 1067 & 23 & 9 & $v_{\mathrm{CN}}(31)+v_{\mathrm{CC}}(23)$ \\
\hline 1013 & 5 & 8 & $v_{\mathrm{CC}}(42)$ \\
\hline 1007 & 1 & 6 & $v_{\mathrm{CC}}(24)+\delta_{\mathrm{CCH}}(8)+\delta_{\mathrm{CCC}}(12)$ \\
\hline 1006 & 1 & 6 & $v_{\mathrm{cc}}(17)+\delta \mathrm{ccH}(7)+\delta \mathrm{ccc}(19)$ \\
\hline 999 & 4 & 7 & $v_{\mathrm{CC}}(53)$ \\
\hline 965 & 0 & 1 & $\Gamma_{\mathrm{HCCH}}(38)+\Gamma_{\mathrm{CCCH}}(25)+\Gamma_{\mathrm{OCCH}}(8)$ \\
\hline 962 & 1 & 1 & $\Gamma_{\mathrm{HCCH}}(43)+\Gamma_{\mathrm{CCCH}}(21)+\Gamma_{\text {OСсH }}(6)$ \\
\hline
\end{tabular}




\begin{tabular}{|c|c|c|c|}
\hline 946 & 0 & 2 & $\Gamma_{\mathrm{HCCH}}(36)+\Gamma_{\mathrm{CCCH}}(16)$ \\
\hline 941 & 3 & 4 & $\Gamma_{\mathrm{HCCH}}(17)+\Gamma_{\mathrm{CCCH}}(7)$ \\
\hline 938 & 1 & 4 & $v_{\mathrm{CC}}(32)+\Gamma_{\mathrm{HCCH}}(9)$ \\
\hline 913 & 20 & 3 & $v_{\mathrm{CN}}(6)+\delta_{\mathrm{CCH}}(5)$ \\
\hline 898 & 3 & 8 & $v_{\operatorname{cc}}(15)+\delta \operatorname{ccc}(7)$ \\
\hline 877 & 22 & 6 & $\delta_{\operatorname{ccc}}(12)+v_{\operatorname{cc}}(5)$ \\
\hline 846 & 4 & 57 & $v_{\mathrm{CO}}(14)+v_{\mathrm{CC}}(43)$ \\
\hline 837 & 15 & 55 & $v_{\operatorname{co}}(18)+v_{\operatorname{cc}}(20)+\delta \operatorname{ccc}(7)$ \\
\hline 835 & 43 & 45 & $\Gamma_{\mathrm{OCCH}}(14)+\Gamma_{\mathrm{CCCH}}(24)+v_{\mathrm{CO}}(7)$ \\
\hline 827 & 9 & 14 & $\Gamma_{\mathrm{OCCH}}(11)+\Gamma_{\mathrm{CCCH}}(14)+v_{\mathrm{CO}}(5)$ \\
\hline 814 & 21 & 5 & Госсн(21)+ Гсссн(37) \\
\hline 812 & 13 & 5 & $\Gamma_{\text {оссн }}(22)+\Gamma_{\mathrm{CCCH}}(37)$ \\
\hline 773 & 9 & 5 & $v_{\mathrm{CC}}(19)+v_{\mathrm{CO}}(14)+\delta_{\mathrm{CCC}}(5)$ \\
\hline 758 & 23 & 3 & $v_{\operatorname{cc}}(12)+\delta \operatorname{ccN}(7)+v_{\operatorname{CN}}(6)$ \\
\hline 725 & 25 & 5 & $v_{\mathrm{CC}}(9)$ \\
\hline 720 & 10 & 4 & $v_{\mathrm{CC}}(9)$ \\
\hline 714 & 5 & 3 & $v_{\operatorname{cc}}(20)+v_{\operatorname{co}}(7)+\delta \operatorname{ccc}(5)$ \\
\hline 694 & 9 & 3 & $v_{\mathrm{CC}}(9)+\Gamma_{\mathrm{OCNH}}(15)$ \\
\hline 669 & 73 & 17 & $\Gamma_{\text {OCNH }}(15)-\Gamma_{\mathrm{CCNH}}(14)-\Gamma_{\mathrm{HNCH}}(6)$ \\
\hline 643 & 0 & 22 & $\delta_{\operatorname{ccc}}(46)$ \\
\hline 643 & 1 & 22 & $\delta_{\mathrm{ccc}}(44)$ \\
\hline 631 & 51 & 16 & $\Gamma_{\mathrm{CCNH}}(31)+\Gamma_{\mathrm{OCNH}}(13)+\Gamma_{\mathrm{HNCH}}(9)+v_{\mathrm{CC}}(7)$ \\
\hline 606 & 9 & 10 & $\delta_{\mathrm{NCO}}(22)+\delta_{\mathrm{CCO}}(16)$ \\
\hline 579 & 71 & 5 & $\Gamma_{\mathrm{CCNH}}(53)+\Gamma_{\mathrm{HNCH}}(16)+\Gamma_{\mathrm{OCNH}}(13)$ \\
\hline 552 & 35 & 4 & $\Gamma_{\mathrm{CCNH}}(17)+\delta \mathrm{cCC}(7)+\Gamma_{\mathrm{HNCH}}(7)$ \\
\hline 547 & 13 & 4 & $v_{\mathrm{cc}}(7)+\delta_{\operatorname{ccc}}(6)$ \\
\hline 499 & 19 & 6 & $\delta \operatorname{ccc}(4)$ \\
\hline 491 & 3 & 9 & $\delta \operatorname{ccc}(12)$ \\
\hline 465 & 4 & 9 & $\delta_{\mathrm{CNC}}(17)+\delta_{\mathrm{CCO}}(7)$ \\
\hline 447 & 1 & 14 & $\delta_{\mathrm{CCN}}(26)+v_{\mathrm{CN}}(15)+\delta_{\mathrm{CCO}}(6)$ \\
\hline 435 & 3 & 15 & $v_{\mathrm{cc}}(6)+\delta_{\operatorname{ccc}}(11)$ \\
\hline 425 & 4 & 11 & $\delta_{\mathrm{cco}}(31)+\delta_{\operatorname{ccc}}(12)$ \\
\hline 423 & 8 & 12 & $\delta \operatorname{cco}(36)+\delta \operatorname{ccc}(12)$ \\
\hline 418 & 1 & 13 & $\delta_{\mathrm{cco}}(10)$ \\
\hline 418 & 2 & 13 & $\delta_{\operatorname{cco}}(14)+\Gamma_{\operatorname{cccc}}(14)$ \\
\hline 413 & 23 & 11 & $\delta \mathrm{cco}(27)+\delta_{\mathrm{NCO}}(8)$ \\
\hline 402 & 13 & 6 & $\delta_{\mathrm{cco}}(12)+\delta_{\mathrm{NCO}}(11)$ \\
\hline 346 & 4 & 14 & $\delta_{\mathrm{CCC}}(12)+\Gamma_{\mathrm{CCCH}}(22)$ \\
\hline 339 & 21 & 21 & Гссон(17) \\
\hline 329 & 93 & 19 & $\Gamma_{\text {Ссон }}(90)$ \\
\hline 328 & 106 & 19 & $\Gamma_{\mathrm{CCOH}}(93)$ \\
\hline 312 & 6 & 11 & $\delta \operatorname{ccc}(5)$ \\
\hline 290 & 4 & 5 & $\delta_{\mathrm{ccc}}(28)$ \\
\hline 214 & 1 & 14 & $\Gamma_{\mathrm{CNCC}}(10)+\delta_{\mathrm{CcC}}(25)+\delta_{\mathrm{CCN}}(7)$ \\
\hline 186 & 1 & 26 & $v_{\mathrm{CC}}(13)+\delta_{\mathrm{ccc}}(20)$ \\
\hline 164 & 3 & 19 & $\delta_{\mathrm{CCC}}(17)+\Gamma_{\mathrm{CNCC}}(7)+\Gamma_{\mathrm{CCCN}}(5)$ \\
\hline 155 & 0 & 27 & $\delta \operatorname{ccc}(16)+\Gamma_{0 \mathrm{onc}}(6)+\Gamma_{\mathrm{cncH}}(5)$ \\
\hline 95 & 1 & 106 & $\Gamma_{\mathrm{CNCC}}(21)+\Gamma_{\mathrm{OCNC}}(9)+\Gamma_{\mathrm{CCCN}}(8)+\Gamma_{\mathrm{CNCH}}(7)$ \\
\hline 91 & 2 & 129 & $\Gamma_{\mathrm{CNCC}}(23)+\Gamma_{\mathrm{CCCN}}(10)+\Gamma_{\mathrm{CNCO}}(10)+\Gamma_{\mathrm{CNCH}}(9)+\Gamma_{\mathrm{NCCH}}(6)$ \\
\hline 68 & 1 & 311 & $\Gamma \mathrm{cсcH}(12)+\Gamma \operatorname{cccc}(6)+\Gamma \operatorname{cccN}(5)$ \\
\hline 60 & 2 & 384 & $\Gamma_{\mathrm{CCCH}}(18)+\Gamma_{\mathrm{CCCC}}(12)$ \\
\hline 45 & 1 & 1100 & $\Gamma_{\mathrm{CCCH}}(44)+\Gamma_{\mathrm{CCCC}}(21)$ \\
\hline 39 & 0 & 1260 & $\Gamma_{\mathrm{CCCN}}(8)+\Gamma_{\mathrm{CNCC}}(12)+\Gamma_{\mathrm{CCCH}}(5)$ \\
\hline 32 & 0 & 2370 & $\Gamma_{\mathrm{CCCN}}(7)+\Gamma_{\mathrm{CCCC}}(7)+\Gamma_{\mathrm{NCCH}}(12)+\Gamma_{\mathrm{CCCH}}(11)$ \\
\hline 25 & 0 & 3370 & $\Gamma_{\mathrm{CCCH}}(32)+\Gamma_{\mathrm{CNCC}}(7)+\Gamma_{\mathrm{CCCC}}(7)$ \\
\hline 16 & 0 & 1880 & $\Gamma_{\mathrm{CCCN}}(11)+\Gamma_{\mathrm{NCCH}}(6)+\Gamma_{\mathrm{CCCO}}(6)+\Gamma_{\mathrm{CNCC}}(6)$ \\
\hline
\end{tabular}

Cyclo(Tyr-Tyr) dipeptidinin monomerik formunun hesaplanan IR ve Raman spektrumu Şekil 5' de verilmiştir. Cyclo(Tyr-Tyr) dipeptidinin iki O-H gerilme titreşimi 3571 ve $3570 \mathrm{~cm}^{-1}$ hesaplanmıştır. Bu titreșimler Cyclo(Ser-Ser) için B3LYP/ Cc-pVDZ ile 3557 ve $3555 \mathrm{~cm}^{-1}$ hesaplanmıştır. Deneysel IR ve Raman spektrumunda ise sirasiyla 3323 ve $3321 \mathrm{~cm}^{-1}$ de işaretlenmiştir [28]. Bu çalışmada Cyclo(Tyr-Tyr) dipeptidinin iki N-H gerilme titreşimi 3384 ve 3378 $\mathrm{cm}^{-1}$ hesaplanmıștır. Cyclo(Ala-His) dipeptidinin deneysel IR spektrumunda bu titreșimler 3320, 3228 ve $3190 \mathrm{~cm}^{-1}$ de gözlenmiştir [29].

Cyclo(Tyr-Tyr) dipeptidinin $\mathrm{C}-\mathrm{H}$ gerilme titreșimleri 2898-3066 $\mathrm{cm}^{-1}$ aralığında hesaplanmıştır. Cyclo(AlaHis) dipeptidinin deneysel IR ve Raman spektrumunda bu titreşimler 3132 (Ra); 3080 (IR); 3002 (IR), 2999(Ra); 2985 (IR), 2982 (Ra); 2969 (Ra); 2940 (IR), 2942 (Ra); 2877(IR); 2875 (Ra) and $2859 \mathrm{~cm}^{-1}$ (IR, Ra) de gözlenmiştir [29]. 
Bu çalışmada $v \mathrm{C}=0$ (Amid I) gerilme titreşimleri 1653 ve $1649 \mathrm{~cm}^{-1}$ hesaplanmıştır. Cyclo(Gly-Leu) dipeptidinin deneysel IR spektrumunda bu titreşimler 1683 ve $1654 \mathrm{~cm}^{-1}$ de gözlenmiştir [30].

Amid II modu \%27 PED katkısı ile $1477 \mathrm{~cm}^{-1}$ hesaplanmıștır.

\section{Tartışma ve Sonuç}

$\mathrm{Bu}$ çalışmada cyclo(tyr-tyr) dipeptidinin konformasyon analizi yapılarak en kararlı yedi konformasyonu belirlenmiştir. En kararlı konformasyon (I) incelendiğinde, tirozin amino asitine ait halka kısımlarının birbirlerine yaklaştığı yani dipeptidinin katlanmış formda bulunduğu belirlenmiștir. Tablo 3' de monomerik ve dimerik formların DFT/B3LYP/6-31G(d,p) teori seviyesinde hesaplanan dihedral açı değerleri karşılaştırıldığında dimerik formda DKP halkası üzerindeki bükülmenin daha düzlemsele yaklaștığı görülmektedir. Ayrıca dimerik formda elde edilen moleküller arası hidrojen bağlarının güçlü ve 1.864 ve $1.869 \AA ̊$ A uzunluğunda olduğu hesaplanmıştır.

Cyclo(Tyr-Tyr) dipeptinin monomerik formu için Amid II modu $1477 \mathrm{~cm}^{-1}$ hesaplanmıştır. Bu sonuç Amid II modu üzerine yapılan çalışmalarla uyumludur $[28,31]$.

3-Boyutlu yapı-aktivite ilişkileri analizlerini gerçekleştirmek için moleküle ait konformasyonel özellikleri içeren parametreleri tanımlamak ilaç tasarımı için yeni umut verici ön çalışmalardır.

\section{Teşekkür}

$\mathrm{Bu}$ çalışma, İstanbul Üniversitesi Bilimsel Araștırma Projeleri Yürütücü Sekreterliğinin ÖNAP-2423 numaralı projesi ile desteklenmiştir.

\section{Etik Beyanı}

Bu çalışmada, "Yükseköğretim Kurumları Bilimsel Araştırma ve Yayın Etiği Yönergesi" kapsamında uyulması gerekli tüm kurallara uyulduğunu, bahsi geçen yönergenin "Bilimsel Araştırma ve Yayın Etiğine Aykırı Eylemler" başlı̆̆ı altında belirtilen eylemlerden hiçbirinin gerçekleștirilmediğini taahhüt ederiz.

\section{Kaynakça}

[1] Uthuppan, J., Soni, K. 2013. Conformational analysis: a review. International Journal of Pharmaceutical Sciences and Research, 4(1), 3441.

[2] Udenfriend, S., Meienhofer, J., Hruby, V. J. 2014. Conformation in Biology and Drug Design: The Peptides: Analysis, Synthesis, Biology, 7, Elsevier.

[3] Ström, K., Sjögren, J., Broberg, A., Schnürer, J. 2002. Lactobacillus plantarum MiLAB 393 produces the antifungal cyclic dipeptides cyclo (L-Phe-L-Pro) and cyclo (L-Phe-trans-4-OH-LPro) and 3-phenyllactic acid. Applied and Environmental Microbiology, 68(9), 4322-4327.

[4] Yamazaki, T., Nunami, K. I., Goodman, M. 1991. Cyclic retro-inverso dipeptides with two aromatic side chains. II. Conformational analysis. Biopolymers: Original Research on Biomolecules, 31(13), 1513-1528.

[5] Ovchinnikov, Y. A., Ivanov, V. T. 1982. The Proteins. ss 307-642. Neurath, H., Hill, R. L. ed. 1982. Academic Press, New York.

[6] Karanam, G., Arumugam, M. K. 2020. Reactive oxygen species generation and mitochondrial dysfunction for the initiation of apoptotic cell death in human hepatocellular carcinoma HepG2 cells by a cyclic dipeptide Cyclo (-ProTyr). Molecular Biology Reports, 47(5), 33473359.

[7] Zainullina, L. F., Ivanova, T. V., Gudasheva, T. A., Vakhitova, Y. V., Seredenin, S. B. 2020. Effect of Neuropeptide Cyclo-L-Prolylglycine on Cell Proliferative Activity. Bulletin of Experimental Biology and Medicine, 169(3), 347-350.

[8] Şimşek, A., Kılıç, B. 2016. Et kaynaklı biyoaktif peptitler ve fonksiyonel özellikleri. Gıda, 41(4), 267-274.

[9] Gao, X., Li, X., Yan, P., Sun, R., Kan, G., Zhou, Y. 2018. Identification and functional mechanism of novel angiotensin I converting enzyme inhibitory dipeptides from Xerocomus badius cultured in shrimp processing waste medium. BioMed Research International, ID: 5089270.

[10] Wu, H., He, H. L., Chen, X. L., Sun, C. Y., Zhang, Y. Z., Zhou, B. C. 2008. Purification and identification of novel angiotensin-I-converting enzyme inhibitory peptides from shark meat hydrolysate. Process Biochemistry, 43(4), 457461.

[11] Nakashima, Y., Arihara, K., Sasaki, A., Mio, H., Ishikawa, S., Itoh, M. 2002. Antihypertensive activities of peptides derived from porcine skeletal muscle myosin in spontaneously hypertensive rats. Journal of Food Science, 67(1), 434-437.

[12] Lee, S. H., Qian, Z. J., Kim, S. K. 2010. A novel angiotensin I converting enzyme inhibitory peptide from tuna frame protein hydrolysate and its antihypertensive effect in spontaneously hypertensive rats. Food Chemistry, 118(1), 96102.

[13] de la Torre, B. G., Albericio, F. 2020. Peptide Therapeutics 2.0. Molecules, 25(10), 2293.

[14] Kilian, G., Jamie, H., Brauns, S. C. A., Dyason, K., Milne, P. J. 2005. Biological activity of selected 
tyrosine-containing 2,5-diketopiperazines. Die Pharmazie-An International Journal of Pharmaceutical Sciences, 60(4), 305-309.

[15] Rajput, S., McLean, K. J., Poddar, H., Selvam, I. R., Nagalingam, G., Triccas, J. A., Levy, C. W., Munro, A. W., Hutton, C. A. 2019. Structure-activity relationships of cyclo (L-tyrosyl-L-tyrosine) derivatives binding to Mycobacterium tuberculosis CYP121: iodinated analogues promote shift to high-spin adduct. Journal of Medicinal Chemistry, 62(21), 9792-9805.

[16] IUPAC-IUB. 1971. Commission on Biochemical Nomenclature, Biochim. Biochimica et Biophysica Acta, 121.

[17] Maksumov, I. S., Ismailova, L. I., Godjaev, N. M. 1983. The program for semiempirical calculation of conformations of the molecular complexes. Journal of Structural Chemistry, 24(4), 647-648.

[18] Popov, E. M. 1985. An approach to the problem of the structuro-functional organization of natural peptides. Molekuliarnaia Biologiia, 19(4), 1107-1138.

[19] Popov, E. M., Godjaev, N. M., Ismailova, L. I., Musaev, S. M., Aliev, R. E., Akhmedov, N. A., Maksumov, I. S. 1982. A-Priori calculation of spatial structure of bovine pancreatic trypsininhibitor. Bioorganicheskaya Khimiya, 8(6), 776816.

[20] Frisch, M. J., Trucks, G. W., Schlegel, H. B., Scuseria, G. E., Robb, M. A., Cheeseman, J. R., Replogle, J. A. 2003. Software for Computational Chemistry; Gaussian Inc.: Pittsburgh, PA, USA.

[21] Becke, A. D. 1993. Density-functional thermochemistry, III. The role ofexact exchange. The Journal of Chemical Physics, 98(7), 56485652 .

[22] Sundius, T. 1990. Molvib -A flexible program for force field calculations. Journal of Molecular Structure, 218, 321-326.

[23] Sundius, T. 2002. Scaling of ab initio force fields by MOLVIB. Vibrational Spectroscopy, 29, 89-95.

[24] Istvan, K. 2002. Simirra, A program for simulation of IR and Raman Spectra. Chemical Research Center.,Budapeşte.

[25] Corey, R. B. 1938. The crystal structure of diketopiperazine. Journal of the American Chemical Society, 60(7), 1598-1604.

[26] Degeilh, R., Marsh, R. E. 1959. A refinement of the crystal structure of diketopiperazine (2,5piperazinedione). Acta Crystallographica, 12(12), 1007-1014.

[27] Dorset, D. L. 2010. Direct methods and refinement in electron and X-ray crystallography-diketopiperazine revisited. Zeitschrift für Kristallographie International Journal for Structural, Physical, and Chemical Aspects of Crystalline Materials, 225(2-3), 8693.

[28] Mendham, A. P., Dines, T. J., Snowden, M. J., Withnall, R., Chowdhry, B. Z. 2009. IR/Raman spectroscopy and DFT calculations of cyclic diamino acid peptides. Part III: Comparison of solid state and solution structures of cyclo (LSer-L-Ser). Journal of Raman Spectroscopy, 40(11), 1508-1520.

[29] Celik, S., Yilmaz, G., Ozel, A. E., Akyuz, S. 2020. Structural and spectral analysis of anticancer active cyclo (Ala-His) dipeptide. Journal of Biomolecular Structure and Dynamics, 1-13.

[30] Celik, S., Ozel, A. E., Akyuz, S. 2016. Comparative study of antitumor active cyclo (Gly-Leu) dipeptide: a computational and molecular modeling study. Vibrational Spectroscopy, 83, 57-69.

[31] Mendham, A. P., Dines, T. J., Snowden, M. J., Chowdhry, B. Z., Withnall, R. 2009. Vibrational spectroscopy and DFT calculations of diaminoacid cyclic peptides. Part I: Cyclo(Gly-Gly), cyclo(L-Ala-L-Ala) and cyclo(L-Ala-Gly) in the solid state and in aqueous solution. Journal of Raman Spectroscopy, 40(11), 1478-1497. 